\title{
DESENVOLVIMENTO HUMANO E SUSTENTÁVEL NA PERSPECTIVA DA PESQUISA ACADÊMICA E NA ATUAÇÃO LEGISLATIVA
}

http://dx.doi.org/10.21527/2176-6622.2018.50.87-101

Recebido em: 4/8/2018

Aceito em: 28/9/2018

\section{Clarissa Bueno Wandscheer}

Doutora em Direito Econômico e Socioambiental (2011), mestre em Direito Econômico e Social (2003) e graduada em Direito (2001) pela Pontifícia Universidade Católica do Paraná. Professora da Universidade Positivo e integrante do Centro de Pesquisa Jurídica e Social (CPJUS) com o projeto de Pesquisa Inovações Tecnológicas, Econômicas e Jurídicas para a Sustentabilidade. Membro do Grupo de Pesquisa em Direito, Tecnologia e Desenvolvimento: organizações econômicas e sociais (Universidade Positivo) e membro do Grupo de Pesquisa em Meio Ambiente: sociedades tradicionais e sociedade hegemônica. Orcid: <http://orcid.org/0000-0002-8593-5838>. clarissa.wandscheer@up.edu.br

\section{Aline Dobrovolski Norberto}

Advogada. Bacharel em Direito pela Universidade Positivo. Participou do programa de bolsas meritórias do Núcleo de Estudos Jurídicos e Sociais (Nejus) da Universidade Positivo em 2017. alinedobrovolskinorberto@hotmail.com

\section{Ayumi Stella Nanami}

Estudante de Direito pela Universidade Positivo. Participou do programa de bolsas meritórias do Núcleo de Estudos Jurídicos e Sociais (Nejus) em 2017 e integrante do Programa de Iniciação Científica (PIC), ciclo 2017-2018, da Universidade Positivo. ayuminanami@hotmail.com

\section{RESUMO}

O presente artigo objetiva apresentar a atividade acadêmica e legislativa acerca do desenvolvimento sustentável e humano. Ou seja, se há um reflexo da pesquisa acadêmica e das preocupações levantadas com o que é produzido no legislativo federal. Para tanto o procedimento metodológico adotado envolveu essencialmente um levantamento quantitativo de artigos científicos publicados em revistas indexadas pelo Qualis B2, B1, A2 e A1 e o levantamento legislativo a partir do material disponível no site oficial da Presidência da República. As buscas realizadas no ambiente acadêmico e legislativo envolveram as seguintes palavras-chave: desenvolvimento humano, desenvolvimento sustentável, sustentabilidade, meio ambiente, ambiente e cidades. Também há a preocupação em apresentar a problemática do desenvolvimento sustentável a partir dos Objetivos do Desenvolvimento Sustentável (ODS) 2030 e considerações sobre o desenvolvimento humano como forma de identificar a relevância do tema e a necessidade de estar presente na agenda atual do governo e da sociedade. 0 presente trabalho está estruturado inicialmente com uma discussão sobre a relação do desenvolvimento humano com a sustentabilidade e o meio ambiente; na segunda parte uma apresentação dos procedimentos metodológicos adotados para a pesquisa; na terceira parte a apresentação e discussão dos dados levantados nos ambientes acadêmico e legislativo e, finalmente, as considerações finais e as referências utilizadas.

Palavras-chave: Desenvolvimento humano. Desenvolvimento sustentável. Meio ambiente. Dados acadêmicos. Dados legislativos.

\section{HUMAN AND SUSTAINABLE DEVELOPMENT IN THE PERSPECTIVE OF ACADEMIC RESEARCH AND LEGISLATIVE ACTION}

\section{ABSTRACT}

This article aims to present academic and legislative concern about sustainable and human development. That is, if there is a reflection of the academic research and the concerns raised with what is produced in the Brazilian Congress. For this, the methodological procedure adopted essentially involved a doctrinal survey of scientific articles published in journals indexed by Qualis B2, B1, A2 and A1. And the legislative survey from the material available on the official website of the Presidency of the Republic. The research carried out in the academic and legislative environment involved the following keywords: human development, sustainable development, sustainability, environment and cities. There is also a concern to present the issue of sustainable development from the Sustainable Development Objectives (ODS) 2030 and considerations on human development as a way of identifying the relevance of the theme and the need to be present in the current agenda of government and society. The present work is structured with a discussion about the relation of the human development with the sustainability and the environment; in the second part the presentation of methodological procedures for this research; in the third, the presentation and discussion of the Legislative performance and Academic data; and, finally, the conclusion and references used in this research.

Keywords: Human development. Sustainable development. Environmental. Academic data. Legislative data.

\section{SUMÁRIO}

1 Introdução. 2 Desenvolvimento Humano, Meio Ambiente e Sustentabilidade no Contexto Desta Pesquisa. 3 Apontamentos Metodológicos. 4 Análise dos Dados. 4.1 Dados Bibliográficos, Palavras-Chave e as Relações Encontradas. 4.2 Dados Normativos e Atuação do Legislativo Federal. 5 Considerações Finais. 6 Referências. 


\section{INTRODUÇÃO}

A ideia de desenvolvimento sustentável, assim como a preocupação com a sustentabilidade teve forte expressão somente nas últimas décadas do século passado, com a Conferência de Estocolmo, em 1972, e busca o equilíbrio entre a redução da degradação ambiental e o desenvolvimento econômico mundial, ou seja, uma melhor racionalidade ambiental.

O desenvolvimento sustentável é mais que crescimento. Ele exige uma mudança no teor do crescimento, a fim de torná-lo menos intensivo de matérias-primas e energia, e mais equitativo em seu impacto. Tais mudanças precisam ocorrer em todos os países, como parte de um pacote de medidas para manter a reserva de capital ecológico, melhorar a distribuição de renda e reduzir o grau de vulnerabilidade em relação às crises econômicas (BRUNDTLAND, 1991, p. 56) e ambientais.

Dessa forma, pretende-se neste texto apresentar o que se encontrou como atividade acadêmica acerca do tema e de que forma os conteúdos relacionados à questão se combinam entre si e se há uma coincidência dessas preocupações em âmbito Legislativo federal. Ou seja, se há um reflexo da pesquisa acadêmica e das preocupações levantadas com o que é produzido no Legislativo federal.

As hipóteses apresentadas para esse trabalhado foram: (a) se há uma correlação entre a pesquisa acadêmica e a atuação legislativa sobre a temática proposta e (b) se há uma confluência das ações acadêmica e legislativa para a concretização das agendas internacionais sobre a temática proposta.

Para isso o procedimento metodológico adotado envolveu essencialmente um levantamento doutrinário de artigos científicos publicados em revistas indexadas pelo Qualis e o levantamento legislativo a partir do material disponível no site oficial da Presidência da República. A temática da pesquisa, em ambos os ambientes, concentrou-se no desenvolvimento humano e desenvolvimento sustentável.

A busca dos artigos concentrou-se em revistas indexadas no Qualis com classificação em B2, B1, A1 e A2, envolvendo as publicações nos periódicos de 2010 a 2017. O ano de início das pesquisas, 2010, justifica-se tendo em vista que naquele ano foi apresentado pela Organização das Nações Unidas (ONU), via Programa das Nações Unidas para o Desenvolvimento (Pnud), o Relatório de Desenvolvimento Humano 2010 - A Verdadeira Riqueza das Nações: Vias para o Desenvolvimento Humano. E neste documento consta a preocupação de que somente a análise do Produto Interno Bruto (PIB) e do (tradicional) Índice de Desenvolvimento Humano (IDH) são insuficientes para analisar o desenvolvimento humano e, portanto, deveria ser incluída, entre outras, a questão da sustentabilidade.

$O$ referido relatório defende a necessidade de que a sustentabilidade seja incorporada como um elemento para a formação do IDH. Por isso, "o âmbito desta análise [IDH] estava incompleto porque o desenvolvimento humano tem um alcance muito mais vasto. A capacitação, a igualdade e $a$ sustentabilidade são algumas das partes intrínsecas da liberdade das pessoas viverem vidas que tenham motivos para valorizar" (PROGRAMA..., 2010, p. 69) (grifado).

A partir dessas informações elaborou-se uma tabela com o resultado das pesquisas, com o objetivo de apresentar as palavras-chave buscadas, bem como quantas vezes apareceram e com quais palavras se relacionam.

As palavras-chave utilizadas para a busca legislativa foram as mesmas adotadas na busca dos artigos científicos nas revistas indexadas que preencheram as condições anteriormente citadas.

Assim, o presente trabalho está estruturado com uma discussão sobre a relação do desenvolvimento humano com a sustentabilidade e o meio ambiente; na segunda parte uma apresentação dos procedimentos metodológicos adotados para a pesquisa; na terceira parte a apresentação e discussão dos dados levantados nos ambientes acadêmico e legislativo e, finalmente, as considerações finais e as referências utilizadas.

\section{DESENVOLVIMENTO HUMANO, MEIO AMBIENTE E SUSTENTABILIDADE NO CONTEXTO DESTA PESQUISA}

Um dos grandes desafios está em harmonizar o desenvolvimento sustentável com o desenvolvimento humano, garantindo qualidade de vida e acesso aos serviços sociais básicos. Diante disso, os Relatórios de Desenvolvimento Humano publicados pelo Programa das Nações Unidas para o Desenvolvimento apresentam 
relevância, tendo em vista que se trata de um redirecionamento das ações do poder público local, a fim de expandir o desenvolvimento humano, principalmente para as populações mais pobres. Assim, em razão de o desenvolvimento sustentável objetivar coexistência harmônica entre economia e meio ambiente, a sustentabilidade compreende crescimento com desenvolvimento econômico, social e ambiental. Aliás, segundo o autor Amartya Sen, o desenvolvimento só é possível quando não há a privação das liberdades humanas. Ou seja, "o desenvolvimento tem de estar relacionado sobretudo com a melhora da vida que levamos e as liberdades que desfrutamos" (SEN, 2000, p. 29).

Também importa destacar que não há uma receita pronta para o desenvolvimento humano e sustentável. Cada país, região e cidade deverá encontrar seu próprio modo de atingir esses objetivos, respeitando suas estruturas nacionais, pois o "termo 'desenvolvimento' denota um processo complexo, cujos fins devem ser as pessoas mesmas, com os seus almejados objetivos, estilos e qualidades de vida" (PINHEIRO, 2012, p. 12), que serão necessariamente diferentes conforme seus contextos sociais, econômicos e ambientais.

Uma das formas de expressar essas diferenças e preferências nacionais é por meio da pauta legislativa nacional e, também, pela preocupação acadêmica refletida na pesquisa científica.

Por isso a necessidade de que cada país e região encontre um equilíbrio próprio para suas atividades de produção e consumo, que impactam no ambiente e na qualidade de vida das pessoas. Sachs entende o progresso científico como uma forma de propiciar aos países em desenvolvimento "seus próprios padrões endógenos de desenvolvimento mais justos e, ao mesmo tempo, com maior respeito à natureza (SACHS, 2002, p. 42)."

(...) a natureza não pode mais ser concebida sem a sociedade, a sociedade não mais sem a natureza. As teorias sociais do século XIX conceberam a natureza como algo essencialmente predeterminado, designado, associal. O próprio processo de industrialização refutou estas suposições, ao mesmo tempo em que as tornou historicamente falsas. No final do século XX, a "natureza" nem é designada, tendo-se transformado em produto social e, sob as condições naturais de sua reprodução, na combalida ou ameaçada estrutura interna do universo civilizatório. Todavia, isto implica dizer: destruições da natureza, integradas à circulação universal da produção industrial, deixam de ser "meras" destruições da natureza e passam a ser elemento constitutivo da dinâmica social, econômica e política. $O$ imprevisto efeito colateral da socialização da natureza é a socialização das destruições e ameaças incidentes sobre a natureza, sua transformação em contradições e conflitos econômicos, sociais e políticos: danos às condições naturais de vida convertem-se em ameaças globais para as pessoas, em termos medicinais, sociais e econômicos - com desafios inteiramente novos para as instituições sociais e políticas da altamente industrializada sociedade global (BECK, 2011, p. 98-99).

Com isso é possível perceber a inter-relação entre o sistema econômico, as atividades empresariais, os padrões de consumo (individuais ou de grupos) para se atingir a sustentabilidade e o desenvolvimento humano.

Assim, "o consumo e a produção precisam ser reestruturados completamente, numa relação inescapável do estilo de vida" (FREITAS, 2012, p. 66) e isso será diferente para cada país e região.

Importante destacar que está, também, presente na Constituição Brasileira, no artigo 225, ao explicitar o dever de defender e preservar o meio ambiente ecologicamente equilibrado para as presentes e futuras gerações. Principalmente com a constatação de que os recursos naturais não são infinitos e estão mostrando atualmente seus limites de exploração, com o esgotamento de poços d'água, petróleo, minas de metais, etc.

A doutrina ambiental é majoritária em reconhecer a presença do princípio do desenvolvimento sustentável no ordenamento pátrio. Dessa forma, para o desenvolvimento harmônico do homem com o meio ambiente faz-se cada vez mais necessário o desenvolvimento de tecnologias que propiciem a utilização racional, controlada e equilibrada dos recursos naturais. Nas palavras de Fiorillo (2017, p. 67): "Busca-se com isso a coexistência harmônica entre economia e meio ambiente. Permite-se o desenvolvimento, mas de forma sustentável, planejada, para que os recursos hoje existentes não se esgotem ou tornem-se inócuos. " Ou, ainda, pode ser visto com o objetivo de "melhorar a qualidade de vida humana dentro dos limites da capacidade de suporte dos ecossistemas (MILARÉ, 2004, p. 49)." 


\section{Debate}

Esse princípio influencia a noção que se apresenta de desenvolvimento na sociedade brasileira, tendo em vista que o Estado nacional formou-se baseado em uma teoria liberal de Estado. Assim sendo, "a proteção do meio ambiente e o fenômeno desenvolvimentista passaram a fazer parte de um objetivo comum, pressupondo a convergência de objetivos das políticas de desenvolvimento econômico, social, cultural e de proteção ambiental" (FIORILLO, 2017, p. 68).

O desenvolvimento sustentável busca o equilíbrio entre o desenvolvimento econômico com a manutenção e a qualidade do meio ambiente, por isso o relacionamento inevitável do artigo 225 como artigo 170 da Constituição Federal, este por tratar a ordem econômica e estabelecer entre os seus princípios a defesa do meio ambiente (inciso $\mathrm{V}$ ).

"Não há dúvida de que o desenvolvimento econômico também é um valor precioso da sociedade. Todavia, a preservação ambiental e o desenvolvimento econômico devem coexistir, de modo que aquela não acarrete a anulação deste" (FIORILLO; FERREIRA, 2017, p. 470).

Não se pretende esgotar os desdobramentos do desenvolvimento sustentável e da sustentabilidade neste trabalho, mas demonstrar que está presente como diretriz constitucional e, portanto, além da ordem internacional os legisladores estão vinculados aos mandamentos constitucionais e devem atuar para a sua concretização.

\section{Dessa forma:}

É fundamental, antes de mais, observar que o escopo básico da Constituição Federal é a proteção do meio ambiente enquanto espaço de vida humana. Em outras palavras, o objeto da tutela é o homem na sua relação com o meio.

Nesse sentido, indicando a defesa do meio ambiente como princípio da ordem econômica reforça esse aspecto. Logo, imperativa a conclusão de que a proteção do meio ambiente deve estar aliada ao progresso econômico, e vice-versa, constituindo, por esse caminho, a noção do chamado desenvolvimento sustentável (ARAÚJO; NUNES JR., 2004, p. 427).

De outro lado, quando se fala em desenvolvimento humano, este está diretamente ligado a aspectos qualitativos, ou em outras palavras, ligado às pessoas, principalmente no que diz respeito à dignidade da pessoa humana, o que, por consequência, assegura a sua íntima relação com a garantia dos direitos fundamentais de cada indivíduo.

Nesse sentido, "a defesa do meio ambiente, embora adote como causa primária no plano normativo, nos valores sociais do trabalho e da livre iniciativa (artigo 10, IV) necessita respeitar a dignidade da pessoa humana como superior fundamento constitucional (artigo 10, III). (FIORILLO; FERREIRA, 2017, p. 465).

Segundo a Organização das Nações Unidas, o conceito de desenvolvimento humano considera que apenas o crescimento econômico não é suficiente para auferir o desenvolvimento de uma nação, uma vez que a renda é um dos meios para tanto e não o seu fim.

No ano de 2015 foi criada a Agenda 2030, que se caracteriza por ser um plano de alcance universal para o desenvolvimento sustentável, com a presença de objetivos e metas. Ou seja, cada país analisa a sua carência e promove ações a fim de alcançar o pleno desenvolvimento; buscam os objetivos, mas considerando a realidade nacional de cada país; são competitivos, mas de maneira sustentável. Além disso, são imprescindíveis a cooperação internacional e a governança global, o que refletirá no aumento da participação da sociedade e, consequentemente, no alcance da sustentabilidade.

No Brasil, embora exista a constitucionalização do direito ao meio ambiente ecologicamente equilibrado, em que este é tratado como um direito fundamental, ainda há a deficiência de estratégias voltadas ao desenvolvimento sustentável, além da verificação da baixa efetividade das políticas públicas ambientais e um aumento significativo nas desigualdades sociais, conforme informado no Relatório Voluntário do Governo Brasileiro para os Objetivos do Desenvolvimento Sustentável (ODS):

No entanto, como resultado da crise econômica recente, os índices de pobreza e extrema pobreza voltaram a subir em 2015, quando comparados a 2014, tendo o percentual de pobres no Brasil oscilado de $6,5 \%$ para $7,8 \%$ no período, enquanto os extremamente pobres passaram de $2,6 \%$ da população para cerca de $4 \%$ (RELATÓRIO..., 2017, p. 52). 
Além disso, o relatório brasileiro sobre ODS elegeu como prioridades os objetivos: 1 - acabar com a pobreza em todas as suas formas, em todos os lugares; 2 - acabar com a fome, alcançar a segurança alimentar e melhoria da nutrição e promover a agricultura sustentável; 3 - assegurar uma vida saudável e promover o bem-estar para todos, em todas as idades; 5 - alcançar a igualdade de gênero e empoderar todas as mulheres e meninas; 9 - construir infraestrutura resiliente, promover a industrialização inclusiva e sustentável e fomentar a inovação; 14 - conservação e uso sustentável dos oceanos, dos mares e dos recursos marinhos para o desenvolvimento sustentável e 17 - fortalecer os meios de efetivar e revitalizar a parceria global para o desenvolvimento sustentável.

\section{APONTAMENTOS METODOLÓGICOS}

Optou-se pela pesquisa empírica do Direito a fim de descrever como a sociedade funciona. Especificamente nesse caso como a sociedade é observada a partir da atuação acadêmica e da atuação do Parlamento federal.

Vale destacar que a "investigação empírica se refere ao processo de observação cautelosa do mundo externo para o propósito de elaboração de descrições válidas - representações - desse mundo" (TRUBEK; ESSER, 2014, p. 236).

A atuação acadêmica foi mensurada quantitativamente a partir das produções científicas publicadas em Revistas indexadas pelos Qualis dentro do padrão B2, B1, A2 e A1. Dessa forma, as revistas indexadas para o Direito e de acesso aberto, disponíveis no período da pesquisa, ou seja, em agosto de 2017, e validadas na última avaliação quadrienal Qualis (2013-2016), foram acessadas. As revistas selecionadas, se comparadas com as atualmente disponíveis no site da Qualis, representam uma amostragem variada do acervo a fim de permitir uma primeira aproximação entre a atuação acadêmica e a legislativa.

Nas revistas selecionadas o critério de busca envolveu as seguintes palavras-chave: desenvolvimento humano, desenvolvimento sustentável, sustentabilidade, meio ambiente, ambiente e cidades. A pesquisa foi realizada em 90 revistas indexadas conforme padrão supra-referido, mas o resultado das buscas foi positivo em 62 delas, conforme Tabela 1.

Tabela 1 - Revistas selecionadas pelo critério de busca

\begin{tabular}{|c|c|}
\hline 1 & Novos Estudos Jurídicos - NEJ \\
\hline 2 & Revista Brasileira de Direito Animal \\
\hline 3 & Veredas do Direito \\
\hline 4 & Sequência (UFSC) \\
\hline 5 & Revista Jurídica da Presidência \\
\hline 6 & Revista Direitos Fundamentais e Democracia \\
\hline 7 & Revista Direito, Estado e Sociedade \\
\hline 8 & Revista de Direito Brasileira \\
\hline 9 & Revista Direito GV \\
\hline 10 & Revista Direito e Práxis \\
\hline 11 & Revista Brasileira de Direito (Imed) \\
\hline 12 & Revista de Direito da Cidade \\
\hline 13 & Revista de Direitos e Garantias Fundamentais \\
\hline 14 & Revista do Direito (Rev. Jur. Unisc) \\
\hline 15 & A\&C - Revista de Direito Administrativo e Constitucional \\
\hline 16 & Revista Culturas Jurídicas \\
\hline 17 & Revista da Faculdade de Direito da Universidade Federal de Goiás \\
\hline 18 &
\end{tabular}




\begin{tabular}{|c|c|}
\hline 19 & Civilística \\
\hline 20 & Economic Analysis of Law Review \\
\hline 21 & Revista da Faculdade de Direito da UFPR \\
\hline 22 & Revista Brasileira de Estudos Políticos \\
\hline 23 & Revista de Direito Internacional \\
\hline 24 & Direito Público (IDP) \\
\hline 25 & Revista Espaço Jurídico \\
\hline 26 & Revista da Faculdade de Direito da Uerj \\
\hline 27 & Revista Quaestio luris \\
\hline 28 & Argumentum \\
\hline 29 & Revista de Direito Administrativo FGV \\
\hline 30 & Scientia luris \\
\hline 31 & Revista Direito \& Paz \\
\hline 32 & Redes \\
\hline 33 & Polis: Revista Latinoamericana \\
\hline 34 & Revista de Direito Econômico e Socioambiental \\
\hline 35 & Estudos Avançados \\
\hline 36 & Revista de Economia Política \\
\hline 37 & Caderno de Relações Internacionais \\
\hline 38 & Revista Duc In Altum - Cadernos de Direito \\
\hline 39 & Revista da Faculdade de Direito do Sul de Minas \\
\hline 40 & Revista Direitos Humanos e Democracia \\
\hline 41 & Revista Opinião Jurídica \\
\hline 42 & Arel Faar \\
\hline 43 & Revista Direito Ambiental e Sociedade \\
\hline 44 & Revista Thesis Juris \\
\hline 45 & Revista Jurídica - CCJ \\
\hline 46 & Revista Direito e Justiça - Reflexões Sociojurídicas \\
\hline 47 & Revista do Programa de Pós-Graduação em Direito da UFC - Nomos \\
\hline 48 & Revista de Estudos e Pesquisas Avançadas do Terceiro Setor - Repats \\
\hline 49 & Revista Prisma Jurídico \\
\hline 50 & Revista Jurídica Unicuritiba \\
\hline 51 & Pensar - Revista de Ciência Jurídica \\
\hline 52 & Revista Prim@ Facie \\
\hline 53 & Revista Jurídica Cesumar \\
\hline 54 & Revista Em Tempo \\
\hline 55 & Revista do Direito Público \\
\hline 56 & Revista Meritum \\
\hline 57 & Revista Jurídica da FA7 \\
\hline 58 & Argumenta Journal Law \\
\hline 59 & Revista da Faculdade Mineira de Direito \\
\hline
\end{tabular}




\begin{tabular}{|c|c|}
\hline 60 & Revista Brasileira de Políticas Públicas \\
\hline 61 & Revista da AGU \\
\hline 62 & Revista de Informaça Legislativa - RIL \\
\hline
\end{tabular}

Fonte: Elaborada pelos autores.

Nas demais revistas não foi constatada a utilização dos termos de pesquisa selecionados para esse trabalho.

O tema proposto para a pesquisa caracteriza-se pela seleção de valores e critérios estabelecidos previamente à busca dos dados. Esses valores são justificados conforme fundamentos apresentados no tópico anterior. Vale destacar que são importantes para o momento histórico não só do Brasil, mas da humanidade.

“Isso significa que valores, conhecimentos e critérios de avaliação são 'historicizados' e 'pluralizados': há uma multidão de valores, perspectivas de conhecimento e critérios; estes elementos são diferentes entre sociedades e ao longo do tempo; (...)" (TRUBEK; ESSER, 2014, p. 237). Por isso, a necessidade de um recorte temporal e de temática a ser pesquisada.

Na atuação legislativa optou-se pela do Congresso Nacional tendo em vista o impacto de suas leis, decorrente do sistema federativo, em que todos os Estados e municípios são afetados e, por vezes, impondo ações positivas para as entidades federativas e outras abrindo a possibilidade de que cada uma regule à sua maneira as questões de desenvolvimento humano e sustentável. Dessa forma, a busca legislativa ocorreu em documentos oficiais consultados como forma de observar as atividades parlamentares e, portanto, para onde apontam as decisões políticas nacionais.

O levantamento da legislação federal inicia-se em 2010, em razão da preocupação internacional indicada no referido relatório do Pnud, e segue até 2017, assim como o levantamento bibliográfico nas revistas científicas.

Dessa forma, a pesquisa propõe-se a um diagnóstico de por onde andam as pesquisas acadêmicas, de um lado, e de outro para onde aponta a ação parlamentar federal. Assim, a atuação do Congresso Nacional revela qual é o rumo das decisões nacionais dentro da temática proposta, enquanto a atuação acadêmica demonstra por onde deveria ser a ação legislativa nacional diante da discussão e preocupação acerca do desenvolvimento humano e da sustentabilidade.

\section{ANÁLISE DOS DADOS}

\subsection{Dados Bibliográficos, Palavras-Chave e as Relações Encontradas}

A pesquisa identificou o aparecimento das palavras-chave (desenvolvimento humano, desenvolvimento sustentável, sustentabilidade, meio ambiente, ambiente, cidades) em diferentes combinações em 403 artigos de 62 revistas indexadas, a maioria dentro do Direito.

A palavra mais citada é meio ambiente, 182 vezes, seguida de sustentabilidade, com 126, depois desenvolvimento sustentável, 108, cidades, 17 e, por fim, desenvolvimento humano, 9.

Como identificado na primeira parte é possível perceber a transversalidade da sustentabilidade, englobando a questão sustentável, pois a palavra aparece relacionada com uma diversidade temática desde ambiente, bem-estar, biotecnologia, consumo, dignidade humana, economia ecológica, economia verde, educação, governança, interesse público, liberdade, planejamento, política pública, propriedade privada, tributação, até questões internacionais como pacto global e transnacionalidade.

O meio ambiente ou ambiente aparece relacionado com ambiente, dano, degradação, desenvolvimento industrial, direitos humanos, ecocentrismo, sociedade de risco, logística reversa, direito fundamental, tutela penal, nanotecnologias, direitos difusos, entre outras.

O desenvolvimento sustentável aparece relacionado à precaução, direito ambiental, consumo, movimentos ecológicos-sociais, empregos verdes, cidadania, dignidade humana, impacto ambiental, degradação, riscos, justiça social, incentivos fiscais, bens ambientais, agricultura familiar, cultura popular, biocombustível, desenvolvimento territorial, solidariedade, resiliência, entre outras. 
Quanto ao termo cidades constam na pesquisa referências à democracia, sustentabilidade urbana, desenvolvimento, urbanismo, desenvolvimento sustentável, direitos fundamentais, propriedade, plano diretor, governança e município, estudo de impacto de vizinhança e moradia.

A expressão desenvolvimento humano é a menos citada e quando encontrada está ligada aos termos livre-mercado, capacidades, direito global, direitos humanos, dignidade humana, poder Judiciário e pobreza.

Percebe-se que o desenvolvimento humano, ainda que com impulso da esfera internacional diante do IDH, não é um tema amplamente discutido no Direito, como se observou no levantamento quantitativo das citações encontradas.

As palavras-chave mais populares na busca foram desenvolvimento sustentável e sustentabilidade e com relações temáticas variadas reforçando o desdobramento nos âmbitos ambiental, econômico e social.

Os dados da referida tabela revelam que muito se estuda sobre sustentabilidade, desenvolvimento sustentável e meio ambiente, contudo verifica-se que essa temática pouco tem se relacionado com a noção de cidades (espaço urbano) e desenvolvimento humano.

\subsection{Dados Normativos e Atuação do Legislativo Federal}

Diante da estrutura governamental do Brasil, o poder político desdobra-se e é composto de várias funções exercidas por diferentes órgãos, o que significa dizer que há, portanto, uma distinção entre as funções que são, fundamentalmente, três: a legislativa, a executiva e a judiciária. É por isso que se fala na tripartição das funções do Estado. Em resumo, os poderes Legislativo, Judiciário e Executivo são responsáveis por legislar, julgar e administrar, respectivamente.

Em especial, no que diz respeito ao poder Legislativo, no Brasil, é composto por duas casas: (i) Câmara dos Deputados e (ii) Senado Federal, que são integradas por representantes eleitos pela população por meio das eleições diretas. A função primária e principal do referido poder é a elaboração de novas normas jurídicas, visando a garantir sempre, da melhor forma, o interesse público.

Considerando a atual crise ambiental e a insustentabilidade do modelo de desenvolvimento adotado pela comunidade mundial, que levam à necessidade da adoção de novas medidas e comportamentos para que se garanta o bem-estar social, foi realizada uma pesquisa acerca das medidas legislativas em vigor no Brasil, a fim de analisar a atuação do governo brasileiro no quesito proteção ao meio ambiente, desenvolvimento humano e sustentável.

O período pesquisado compreendeu os anos entre 2010 e 2017, e tal período foi selecionado tendo em vista que o ano de 2010 foi escolhido pela ONU para apresentar o relatório do Pnud com análises sobre o desenvolvimento sustentável. Ao todo, nesse lapso temporal compreendido por 8 anos, foram encontrados 69 atos normativos, dos quais 50 são decretos editados pelo Poder Executivo e 19 são leis em sentido estrito, sejam elas ordinárias ou complementares, elaboradas pelo próprio Poder Legislativo, como se observa na Tabela 2.

Tabela 2 - Atos normativos encontrados na pesquisa

\begin{tabular}{|c|l|l|l|l|c|}
\hline & Ano & Tipos de leis & Número & Ementa & Palavra-chave \\
\hline 1 & 2010 & Decreto & 7.167 & $\begin{array}{l}\text { Regulamenta o Fundo Nacional de Desenvolvimento Florestal - } \\
\text { FNDF, que tem por finalidade fomentar o desenvolvimento de ativi- } \\
\text { dades sustentáveis de base florestal no Brasil e promover a inovação } \\
\text { tecnológica do setor. }\end{array}$ & $\begin{array}{l}\text { Desenvolvimento } \\
\text { sustentável }\end{array}$ \\
\hline 2010 & Decreto & 7.170 & $\begin{array}{l}\text { Promulga o Acordo de Cooperação entre o Governo da República } \\
\text { Federativa do Brasil e o Governo da República do Paraguai para o } \\
\text { Desenvolvimento Sustentável e a Gestão Integrada da Bacia Hidro- } \\
\text { gráfica do Rio Apa, firmado em Brasília, em 11 de setembro de 2006, } \\
\text { com o propósito de melhorar as condições de vida das populações } \\
\text { fronteiriças, assim como de promover o aproveitamento sustentável } \\
\text { dos recursos naturais das áreas limítrofes de acordo com critérios } \\
\text { equitativos. }\end{array}$ & $\begin{array}{l}\text { Destentável } \\
\text { Sustento }\end{array}$ \\
\hline
\end{tabular}




\begin{tabular}{|c|c|c|c|c|c|}
\hline 3 & 2010 & Lei & 12.305 & \begin{tabular}{|l|} 
Institui a Política Nacional de Resíduos Sólidos, sendo alguns de seus \\
objetivos: a proteção da saúde pública e da qualidade ambiental, \\
estímulo à adoção de padrões sustentáveis de produção e consumo \\
de bens e serviços; adoção, desenvolvimento e aprimoramento de \\
tecnologias limpas como forma de minimizar impactos ambientais.
\end{tabular} & Meio ambiente \\
\hline 4 & 2010 & Decreto & 15 & \begin{tabular}{|l|} 
Institui o Plano de Ação para Prevenção e Controle do Desmatamen- \\
to e das Queimadas no Bioma Cerrado
\end{tabular} & Meio ambiente \\
\hline 5 & 2010 & Decreto & 7.378 & $\begin{array}{l}\text { Aprova o Macrozoneamento Ecológico-Econômico da Amazônia Le- } \\
\text { gal - MacroZEE da Amazônia Legal como instrumento de orientação } \\
\text { para a formulação e espacialização das políticas públicas de desen- } \\
\text { volvimento, ordenamento territorial e meio ambiente, assim como } \\
\text { para as decisões dos agentes privados. }\end{array}$ & Meio ambiente \\
\hline 6 & 2011 & Lei & 12.512 & $\begin{array}{l}\text { Institui o Programa de Apoio à Conservação Ambiental e o Programa } \\
\text { de Fomento às Atividades Produtivas Rurais }\end{array}$ & Meio ambiente \\
\hline 7 & 2011 & $\begin{array}{l}\text { Lei comple- } \\
\text { mentar }\end{array}$ & 140 & \begin{tabular}{|l|} 
Fixa normas, nos termos dos incisos III, VI e VII do caput e do pará- \\
grafo único do art. 23 da Constituição Federal, para a cooperação en- \\
tre a União, os Estados, o Distrito Federal e os municípios nas ações \\
administrativas decorrentes do exercício da competência comum \\
relativas à proteção das paisagens naturais notáveis, à proteção do \\
meio ambiente, ao combate à poluição em qualquer de suas formas \\
e à preservação das florestas, da fauna e da flora
\end{tabular} & Meio ambiente \\
\hline 8 & 2012 & Decreto & 7.746 & \begin{tabular}{|l|} 
Regulamenta o art. 30 da Lei no 8.666, de 21 de junho de 1993, para \\
estabelecer critérios, práticas e diretrizes para a promoção do de- \\
senvolvimento nacional sustentável nas contratações realizadas pela \\
administração pública federal, e institui a Comissão Interministerial \\
de Sustentabilidade na Administração Pública - Cisap
\end{tabular} & $\begin{array}{l}\text { Meio ambiente e } \\
\text { desenvolvimento } \\
\text { sustentável }\end{array}$ \\
\hline 9 & 2012 & Decreto & 7.747 & $\begin{array}{l}\text { Institui a Política Nacional de Gestão Territorial e Ambiental de Ter- } \\
\text { ras Indígenas - PNGATI - com o objetivo de garantir e promover a } \\
\text { proteção, a recuperação, a conservação e o uso sustentável dos re- } \\
\text { cursos naturais das terras e territórios indígenas, assegurando a in- } \\
\text { tegridade do patrimônio indígena, a melhoria da qualidade de vida } \\
\text { e as condições plenas de reprodução física e cultural das atuais e } \\
\text { futuras gerações dos povos indígenas, respeitando sua autonomia } \\
\text { sociocultural, nos termos da legislação vigente. }\end{array}$ & Meio ambiente \\
\hline 10 & 2012 & Decreto & 7.794 & $\begin{array}{l}\text { Institui a Política Nacional de Agroecologia e Produção Orgânica, } \\
\text { com o objetivo de integrar, articular e adequar políticas, programas } \\
\text { e ações indutoras da transição agroecológica e da produção orgâni- } \\
\text { ca e de base agroecológica, contribuindo para o desenvolvimento } \\
\text { sustentável e a qualidade de vida da população, por meio do uso } \\
\text { sustentável dos recursos naturais e da oferta e consumo de alimen- } \\
\text { tos saudáveis. }\end{array}$ & $\begin{array}{l}\text { Desenvolvimento } \\
\text { sustentável }\end{array}$ \\
\hline 11 & 2012 & Lei & 12.725 & Dispõe sobre o controle da fauna nas imediações de aeródromos. & Meio ambiente \\
\hline 12 & 2012 & Lei & 12.731 & $\begin{array}{l}\text { Institui o Sistema de Proteção ao Programa Nuclear Brasileiro - Si- } \\
\text { pron - que terá como uma de suas atribuições planejar e coordenar } \\
\text { as ações, em situações de emergência nuclear, que tenham como } \\
\text { objetivo proteger a população e o meio ambiente situados nas pro- } \\
\text { ximidades das instalações nucleares. }\end{array}$ & Meio ambiente \\
\hline 13 & 2013 & Decreto & 7.830 & \begin{tabular}{|l|} 
Dispõe sobre o Sistema de Cadastro Ambiental Rural, o Cadastro \\
Ambiental Rural, estabelece normas de caráter geral aos Programas \\
de Regularização Ambiental, de que trata a Lei no 12.651, de 25 de \\
maio de 2012, e dá outras providências. \\
\end{tabular} & Meio ambiente \\
\hline 14 & 2013 & Decreto & 7.940 & $\begin{array}{l}\text { Promulga o Protocolo Adicional ao Acordo-Quadro Sobre Meio Am- } \\
\text { biente do Mercosul em Matéria de Cooperação e Assistência Frente } \\
\text { a Emergências Ambientais, adotado pela Decisão 14/4 do Conselho } \\
\text { do Mercado Comum, em } 7 \text { de julho de } 2004 \text {. }\end{array}$ & Meio ambiente \\
\hline 15 & 2013 & Decreto & 7.957 & $\begin{array}{l}\text { Institui o Gabinete Permanente de Gestão Integrada para a Proteção } \\
\text { do Meio Ambiente; regulamenta a atuação das Forças Armadas na } \\
\text { proteção ambiental; altera o Decreto no 5.289, de } 29 \text { de novembro } \\
\text { de } 2004 \text { e dá outras providências. }\end{array}$ & Meio ambiente \\
\hline 16 & 2013 & Decreto & 7.992 & $\begin{array}{l}\text { Promulga o Instrumento de Criação do Fundo Reestruturado do } \\
\text { Meio Ambiente Global, firmado em Genebra, em } 16 \text { de março de } \\
1994 \text {. }\end{array}$ & Meio ambiente \\
\hline
\end{tabular}




\begin{tabular}{|c|c|c|c|c|c|}
\hline 17 & 2013 & Decreto & 7.993 & $\begin{array}{l}\text { Promulga a Proposta de Participação do Brasil na Quarta Recompo- } \\
\text { sição dos Recursos do Fundo para o Meio Ambiente Global - GEF-4 } \\
\text { - firmada em 1ㅇ de dezembro de } 2009 \text {. }\end{array}$ & Meio ambiente \\
\hline 18 & 2013 & Lei & 12.805 & $\begin{array}{l}\text { Institui a Política Nacional de Integração Lavoura-Pecuária-Floresta e } \\
\text { altera a Lei } 8.171 \text {, de } 17 \text { de janeiro de } 1991 .\end{array}$ & Meio ambiente \\
\hline 19 & 2013 & Lei & 12.829 & $\begin{array}{l}\text { Cria o Parque Nacional Marinho das Ilhas dos Currais, no Estado do } \\
\text { Paraná. }\end{array}$ & Meio ambiente \\
\hline 20 & 2013 & Lei & 12.854 & $\begin{array}{l}\text { Fomenta e incentiva ações que promovam a recuperação florestal e } \\
\text { a implantação de sistemas agroflorestais em áreas rurais desapro- } \\
\text { priadas e em áreas degradadas, nos casos que especifica. }\end{array}$ & Meio ambiente \\
\hline 21 & 2013 & Lei & 12.862 & $\begin{array}{l}\text { Altera a Lei } \mathrm{n} \text { - } 11.445 \text {, de } 5 \text { de janeiro de } 2007 \text {, que estabelece dire- } \\
\text { trizes nacionais para o saneamento básico, com o objetivo de incen- } \\
\text { tivar a economia no consumo de água. }\end{array}$ & Meio ambiente \\
\hline 22 & 2013 & Decreto & 8.127 & $\begin{array}{l}\text { Institui o Plano Nacional de Contingência para Incidentes de Polui- } \\
\text { ção por Óleo em Águas sob Jurisdição Nacional, altera o Decreto no } \\
4.871 \text {, de } 6 \text { de novembro de } 2003 \text {, e o Decreto no } 4.136 \text {, de } 20 \text { de } \\
\text { fevereiro de } 2002 \text {, e dá outras providências. }\end{array}$ & Meio ambiente \\
\hline 23 & 2013 & Decreto & 8.141 & $\begin{array}{l}\text { Dispõe sobre o Plano Nacional de Saneamento Básico - PNSB - ins- } \\
\text { titui o Grupo de Trabalho Interinstitucional de Acompanhamento da } \\
\text { Implementação do PNSB e dá outras providências. }\end{array}$ & Meio ambiente \\
\hline 24 & 2014 & Decreto & DSN & $\begin{array}{l}\text { Amplia a Reserva Extrativista do Médio Juruá, localizada no municí- } \\
\text { pio de Carauari, Estado do Amazonas. }\end{array}$ & Meio ambiente \\
\hline 25 & 2014 & Decreto & DSN & $\begin{array}{l}\text { Amplia a Reserva Extrativista do Médio Juruá, localizada no municí- } \\
\text { pio de Carauari, Estado do Amazonas. }\end{array}$ & $\begin{array}{l}\text { Meio ambiente; } \\
\text { Recursos naturais }\end{array}$ \\
\hline 26 & 2014 & Decreto & DSN & $\begin{array}{l}\text { Cria a Estação Ecológica Alto Maués, localizada no município de } \\
\text { Maués, Estado do Amazonas. }\end{array}$ & $\begin{array}{l}\text { Meio ambiente; } \\
\text { Ecologia }\end{array}$ \\
\hline 27 & 2014 & Decreto & DSN & $\begin{array}{l}\text { Amplia a Reserva Extrativista Marinha de Araí-Peroba, localizada no } \\
\text { município de Augusto Corrêa, Estado do Pará. }\end{array}$ & $\begin{array}{l}\text { Meio ambiente; } \\
\text { Recursos naturais }\end{array}$ \\
\hline 28 & 2014 & Decreto & DSN & $\begin{array}{l}\text { Cria a Reserva Extrativista Marinha Cuinarana, localizada no municí- } \\
\text { pio de Magalhães Barata, Estado do Pará. }\end{array}$ & $\begin{array}{l}\text { Meio ambiente; } \\
\text { Recursos naturais }\end{array}$ \\
\hline 29 & 2014 & Decreto & DSN & $\begin{array}{l}\text { Cria a Reserva Extrativista Marinha Mocapajuba, localizada no muni- } \\
\text { cípio de São Caetano de Odivelas, Estado do Pará. }\end{array}$ & $\begin{array}{l}\text { Meio ambiente; } \\
\text { Recursos naturais }\end{array}$ \\
\hline 30 & 2014 & Decreto & DSN & $\begin{array}{l}\text { Cria a Reserva Extrativista Marinha Mestre Lucindo, localizada no } \\
\text { município de Marapanim, Estado do Pará. }\end{array}$ & $\begin{array}{l}\text { Meio ambiente; } \\
\text { Recursos naturais }\end{array}$ \\
\hline 31 & 2014 & Decreto & DSN & $\begin{array}{l}\text { Cria o Parque Nacional da Serra do Gandarela, localizado nos muni- } \\
\text { cípios de Nova Lima, Raposos, Caeté, Santa Bárbara, Mariana, Ouro } \\
\text { Preto, Itabirito e Rio Acima, Estado de Minas Gerais. }\end{array}$ & $\begin{array}{l}\text { Meio ambiente; } \\
\text { Parque nacional }\end{array}$ \\
\hline 32 & 2014 & Decreto & DSN & $\begin{array}{l}\text { Cria o Parque Nacional Guaricana, localizado nos municípios de Gua- } \\
\text { ratuba, Morretes e São José dos Pinhais, Estado do Paraná. }\end{array}$ & $\begin{array}{l}\text { Meio ambiente; } \\
\text { Ecologia }\end{array}$ \\
\hline 33 & 2014 & Decreto & DSN & $\begin{array}{l}\text { Cria a Reserva de Desenvolvimento Sustentável Nascentes Geraizei- } \\
\text { ras, localizada nos municípios de Montezuma, Rio Pardo de Minas e } \\
\text { Vargem Grande do Rio Pardo, Estado de Minas Gerais. }\end{array}$ & $\begin{array}{l}\text { Meio ambiente; } \\
\text { Recursos naturais }\end{array}$ \\
\hline 34 & 2014 & Lei & 12.983 & $\begin{array}{l}\text { Altera a Lei no } 12.340 \text {, de } 1 \text { o de dezembro de } 2010 \text {, para dispor sobre } \\
\text { as transferências de recursos da União aos órgãos e entidades dos } \\
\text { Estados, Distrito Federal e municípios para a execução de ações de } \\
\text { prevenção em áreas de risco e de resposta e recuperação em áreas } \\
\text { atingidas por desastres e sobre o Fundo Nacional para Calamidades } \\
\text { Públicas, Proteção e Defesa Civil, e as Leis no } 10.257 \text {, de } 10 \text { de julho } \\
\text { de } 2001 \text {, e } 12.409 \text {, de } 25 \text { de maio de } 2011 \text {, e revoga dispositivos da } \\
\text { Lei no } 12.340 \text {, de } 1 \text { o de dezembro de } 2010 \text {. }\end{array}$ & $\begin{array}{l}\text { Meio ambiente; } \\
\text { Calamidade pú- } \\
\text { blica }\end{array}$ \\
\hline 35 & 2014 & Lei & 13.052 & $\begin{array}{l}\text { Altera o art. } 25 \text { da Lei } n \text { o } 9.605 \text {, de } 12 \text { de fevereiro de } 1998 \text {, que dis- } \\
\text { põe sobre as sanções penais e administrativas derivadas de condu- } \\
\text { tas e atividades lesivas ao meio ambiente e dá outras providências, } \\
\text { para determinar que animais apreendidos sejam libertados priori- } \\
\text { tariamente em seu habitat e estabelecer condições necessárias ao } \\
\text { bem-estar desses animais. }\end{array}$ & $\begin{array}{l}\text { Meio ambiente; } \\
\text { Política do meio } \\
\text { ambiente }\end{array}$ \\
\hline
\end{tabular}




\begin{tabular}{|c|c|c|c|c|c|}
\hline 36 & 2014 & Decreto & DSN & \begin{tabular}{|l|} 
Declara de utilidade pública, para fins do disposto na alínea "b" do \\
inciso VII do caput do art. 3o da Lei no 11.428 , de 22 de dezembro de \\
2006, obra essencial de infraestrutura portuária de interesse nacio- \\
nal destinada ao serviço público de transporte marítimo.
\end{tabular} & $\begin{array}{l}\text { Meio ambiente; } \\
\text { Política do meio } \\
\text { ambiente }\end{array}$ \\
\hline 37 & 2014 & Decreto & 8.235 & $\begin{array}{l}\text { Estabelece normas gerais complementares aos Programas de Regu- } \\
\text { larização Ambiental dos Estados e do Distrito Federal, de que trata } \\
\text { o Decreto no 7.830, de } 17 \text { de outubro de 2012, institui o Programa } \\
\text { Mais Ambiente Brasil, e dá outras providências. }\end{array}$ & $\begin{array}{l}\text { Meio ambiente; } \\
\text { Política do meio } \\
\text { ambiente }\end{array}$ \\
\hline 38 & 2014 & Decreto & 8.330 & $\begin{array}{l}\text { Promulga o acordo internacional de madeiras tropicais, firmado pela } \\
\text { República Federativa do Brasil. }\end{array}$ & Meio ambiente \\
\hline 39 & 2015 & Decreto & 8.423 & $\begin{array}{l}\text { Regulamenta os critérios para a progressão funcional e a promoção } \\
\text { na carreira de Especialista em Meio Ambiente, de que trata a Lei no } \\
10.410 \text {, de } 11 \text { de janeiro de } 2002 \text {, e no Plano Especial de Cargos do } \\
\text { Ministério do Meio Ambiente e do Instituto Brasileiro do Meio Am- } \\
\text { biente e dos Recursos Naturais Renováveis - Ibama - Pecma, de que } \\
\text { trata a Lei no } 11.357 \text {, de } 19 \text { de outubro de } 2006 \text {. }\end{array}$ & Meio ambiente \\
\hline 40 & 2015 & Decreto & 8.505 & $\begin{array}{l}\text { Dispõe sobre o Programa Áreas Protegidas da Amazônia, instituído } \\
\text { no âmbito do Ministério do Meio Ambiente. }\end{array}$ & Meio ambiente \\
\hline 41 & 2015 & Decreto & 8.576 & $\begin{array}{l}\text { Institui a Comissão Nacional para Redução das Emissões de Gases } \\
\text { de Efeito Estufa Provenientes do Desmatamento e da Degradação } \\
\text { Florestal, Conservação dos Estoques de Carbono Florestal, Manejo } \\
\text { Sustentável de Florestas e Aumento de Estoques de Carbono Flores- } \\
\text { tal-REDD+. }\end{array}$ & Meio ambiente \\
\hline 42 & 2015 & Lei & 13.214 & $\begin{array}{l}\text { Abre ao Orçamento Fiscal da União, em favor dos Ministérios dos } \\
\text { Transportes e do Meio Ambiente, crédito suplementar no valor de } \\
\text { R\$ 26.769.407,00, para reforço de dotações constantes da Lei Orça- } \\
\text { mentária vigente. }\end{array}$ & $\begin{array}{l}\text { Meio ambiente; } \\
\text { Orçamento }\end{array}$ \\
\hline 43 & 2015 & Decreto & DSN & $\begin{array}{l}\text { Autoriza o Banco Central do Brasil a doar para a Fundação do Meio } \\
\text { Ambiente do Estado de Santa Catarina - Fatma - fração ideal perten- } \\
\text { cente à União de imóvel localizado no Estado de Santa Catarina, e dá } \\
\text { outras providências. }\end{array}$ & $\begin{array}{l}\text { Meio ambiente; } \\
\text { Doação }\end{array}$ \\
\hline 44 & 2015 & Lei & 13.203 & \begin{tabular}{|l|} 
Dispõe sobre a repactuação do risco hidrológico de geração de \\
energia elétrica, institui a bonificação pela outorga e altera a Lei no \\
10.848, de 15 de março de 2004 , que dispõe sobre a comercializa- \\
ção de energia elétrica, a Lei no $12.783,11$ de janeiro de 2013 , que \\
dispõe sobre as concessões de energia elétrica, e a Lei no 9.478 , de \\
6 de agosto de 1997, que institui o Conselho Nacional de Política \\
Energética.
\end{tabular} & Meio ambiente \\
\hline 45 & 2015 & Lei & 13.123 & $\begin{array}{l}\text { Regulamenta o inciso II do } \S 10 \text { e o } \S 40 \text { do art. } 225 \text { da Constitui- } \\
\text { ção Federal, o Artigo } 1, \text { a alínea j do Artigo } 8 \text {, a alínea c do Artigo } \\
10 \text {, o Artigo } 15 \text { e os } \S \S 3^{\circ} \text { e } 4^{\circ} \text { do Artigo } 16 \text { da Convenção sobre } \\
\text { Diversidade Biológica, promulgada pelo Decreto no } 2.519 \text {, de } 16 \text { de } \\
\text { março de } 1998 ; \text { dispõe sobre o acesso ao patrimônio genético, so- } \\
\text { bre a proteção e o acesso ao conhecimento tradicional associado e } \\
\text { sobre a repartição de benefícios para conservação e uso sustentável } \\
\text { da biodiversidade; revoga a Medida Provisória no } 2.186-16 \text {, de } 23 \text { de } \\
\text { agosto de } 2001 \text { e dá outras providências. }\end{array}$ & Meio ambiente \\
\hline 46 & 2015 & Lei & 13.153 & $\begin{array}{l}\text { Institui a Política Nacional de Combate à Desertificação e Mitigação } \\
\text { dos Efeitos da Seca e seus instrumentos; prevê a criação da Comis- } \\
\text { são Nacional de Combate à Desertificação; e dá outras providências. }\end{array}$ & Meio ambiente \\
\hline 47 & 2015 & Decreto & DSN & $\begin{array}{l}\text { Institui o Comitê de Gestão e Avaliação de Respostas ao desastre } \\
\text { ocorrido nas barragens do Fundão e de Santarém no município de } \\
\text { Mariana, Estado de Minas Gerais, e suas repercussões na bacia do } \\
\text { Rio Doce, atingindo o Estado do Espírito Santo. }\end{array}$ & Meio ambiente \\
\hline 48 & 2015 & Lei & 13.214 & $\begin{array}{l}\text { Abre ao orçamento fiscal da União, em favor dos Ministérios dos } \\
\text { Transportes e do Meio Ambiente, crédito suplementar no valor de } \\
R \$ 26.769 .407,00, \text { para reforço de dotações constantes da lei orça- } \\
\text { mentária. }\end{array}$ & $\begin{array}{l}\text { Meio ambiente; } \\
\text { Orçamento }\end{array}$ \\
\hline 49 & 2015 & Lei & 13.186 & Institui a Política de Educação para o Consumo Sustentável. & Meio ambiente \\
\hline
\end{tabular}




\begin{tabular}{|c|c|c|c|c|c|}
\hline 50 & 2015 & Lei & 13.233 & $\begin{array}{l}\text { Obriga, nas hipóteses que especifica, a veiculação de mensagem de } \\
\text { advertência sobre o risco de escassez e de incentivo ao consumo } \\
\text { moderado de água. }\end{array}$ & $\begin{array}{l}\text { Meio ambiente; } \\
\text { Consumo de água }\end{array}$ \\
\hline 51 & 2015 & Decreto & 8.437 & $\begin{array}{l}\text { Regulamenta o disposto no art. 70, caput, inciso XIV, alínea " } \mathrm{h} \text { ", e } \\
\text { parágrafo único, da Lei Complementar no } 140 \text {, de } 8 \text { de dezembro de } \\
2011 \text {, para estabelecer as tipologias de empreendimentos e ativi- } \\
\text { dades cujo licenciamento ambiental será de competência da União. }\end{array}$ & $\begin{array}{l}\text { Meio ambiente; } \\
\text { Desenvolvimento } \\
\text { sustentável }\end{array}$ \\
\hline 52 & 2016 & Decreto & DSN & $\begin{array}{l}\text { Cria a Reserva Biológica do Manicoré, localizada nos municípios de } \\
\text { Manicoré e Novo Aripuanã, Estado do Amazonas. }\end{array}$ & $\begin{array}{l}\text { Meio ambiente; } \\
\text { Política do meio } \\
\text { ambiente }\end{array}$ \\
\hline 53 & 2016 & Decreto & DSN & $\begin{array}{l}\text { Amplia a Floresta Nacional Amana, no município de Maués, Estado } \\
\text { do Amazonas. }\end{array}$ & $\begin{array}{l}\text { Meio ambiente; } \\
\text { Política do meio } \\
\text { ambiente }\end{array}$ \\
\hline 54 & 2016 & Decreto & DSN & $\begin{array}{l}\text { Cria a Floresta Nacional do Aripuanã, localizada nos municípios de } \\
\text { Apuí, Manicoré e Novo Aripuanã, Estado do Amazonas. }\end{array}$ & $\begin{array}{l}\text { Meio ambiente; } \\
\text { Política do meio } \\
\text { ambiente }\end{array}$ \\
\hline 55 & 2016 & Decreto & DSN & $\begin{array}{l}\text { Cria o Parque Nacional do Acari, localizado nos municípios de Apuí, } \\
\text { Borba e Novo Aripuanã, Estado do Amazonas. }\end{array}$ & $\begin{array}{l}\text { Meio ambiente; } \\
\text { Política do meio } \\
\text { ambiente }\end{array}$ \\
\hline 56 & 2016 & Decreto & DSN & $\begin{array}{l}\text { Cria a Floresta Nacional de Urupadi, no município de Maués, Estado } \\
\text { do Amazonas. }\end{array}$ & Meio ambiente \\
\hline 57 & 2016 & Decreto & 8.773 & $\begin{array}{l}\text { Altera o Decreto no } 6.527 \text {, de } 1 \text { o de agosto de } 2008 \text {, que dispõe so- } \\
\text { bre o estabelecimento do Fundo Amazônia pelo Banco Nacional de } \\
\text { Desenvolvimento Econômico e Social - BNDES. }\end{array}$ & $\begin{array}{l}\text { Meio ambiente; } \\
\text { Política do meio } \\
\text { ambiente }\end{array}$ \\
\hline 58 & 2016 & Decreto & 8.775 & $\begin{array}{l}\text { Dispõe sobre a Área de Proteção Ambiental de Cairuçu, localizada no } \\
\text { município de Paraty, Estado do Rio de Janeiro, criada pelo Decreto no } \\
89.242 \text {, de } 27 \text { de dezembro de } 1983 \text {. } \\
\end{array}$ & $\begin{array}{l}\text { Meio ambiente; } \\
\text { Ecologia }\end{array}$ \\
\hline 59 & 2016 & Decreto & 8.772 & $\begin{array}{l}\text { Regulamenta a Lei no } 13.123 \text {, de } 20 \text { de maio de } 2015 \text {, que dispõe } \\
\text { sobre o acesso ao patrimônio genético, sobre a proteção e o acesso } \\
\text { ao conhecimento tradicional associado e sobre a repartição de be- } \\
\text { nefícios para conservação e uso sustentável da biodiversidade. }\end{array}$ & $\begin{array}{l}\text { Meio ambiente; } \\
\text { Recursos ambien- } \\
\text { tais; Política do } \\
\text { meio ambiente } \\
\end{array}$ \\
\hline 60 & 2016 & Decreto & 8.907 & Aprova o IX Plano Setorial para os Recursos do mar. & $\begin{array}{l}\text { Meio ambiente; } \\
\text { Recursos naturais } \\
\end{array}$ \\
\hline 61 & 2016 & Decreto & 8.834 & $\begin{array}{l}\text { Dispõe sobre o Programa de Revitalização da Bacia Hidrográfica do } \\
\text { Rio São Francisco. }\end{array}$ & $\begin{array}{l}\text { Meio ambiente; } \\
\text { Recursos hídricos }\end{array}$ \\
\hline 62 & 2016 & Decreto & DSN & $\begin{array}{l}\text { Cria o Refúgio de Vida Silvestre do Arquipélago de Alcatrazes no lito- } \\
\text { ral norte do Estado de São Paulo. }\end{array}$ & Meio ambiente \\
\hline 63 & 2016 & Lei & 13.381 & $\begin{array}{l}\text { Abre ao orçamento fiscal da União, em favor do Ministério do Meio } \\
\text { Ambiente, crédito suplementar no valor de } R \$ 20.772 .513,00, \text { para } \\
\text { reforço de dotações constantes da lei orçamentária vigente. }\end{array}$ & $\begin{array}{l}\text { Meio ambiente; } \\
\text { Orçamento }\end{array}$ \\
\hline 64 & 2016 & Decreto & 8.892 & $\begin{array}{l}\text { Cria a comissão nacional para os objetivos de desenvolvimento sus- } \\
\text { tentável. }\end{array}$ & $\begin{array}{l}\text { Meio ambiente; } \\
\text { Desenvolvimento } \\
\text { sustentável }\end{array}$ \\
\hline 65 & 2016 & Decreto & 8.735 & $\begin{array}{l}\text { Dispõe sobre a composição, a estruturação, as competências e o fun- } \\
\text { cionamento do Conselho Nacional de Desenvolvimento Rural Sus- } \\
\text { tentável - Condraf. }\end{array}$ & $\begin{array}{l}\text { Meio ambiente; } \\
\text { Desenvolvimento } \\
\text { rural sustentável } \\
\end{array}$ \\
\hline 66 & 2016 & Decreto & DSN & $\begin{array}{l}\text { Cria o refúgio de vida silvestre do arquipélago de Alcatrazes, no lito- } \\
\text { ral norte do Estado de São Paulo. }\end{array}$ & $\begin{array}{l}\text { Meio ambiente; } \\
\text { Proteção ambien- } \\
\text { tal }\end{array}$ \\
\hline 67 & 2017 & Decreto & DSN & $\begin{array}{l}\text { Institui o Comitê para a Revitalização do Parque Histórico Nacional } \\
\text { dos Guararapes. }\end{array}$ & Meio ambiente \\
\hline 68 & 2017 & Decreto & 8.972 & Institui a Política Nacional de Recuperação da Vegetação Nativa. & Meio ambiente \\
\hline 69 & 2017 & Decreto & 9.082 & Institui o Fórum Brasileiro de Mudança do Clima. & $\begin{array}{l}\text { Meio ambiente; } \\
\text { Clima }\end{array}$ \\
\hline 70 & 2017 & Decreto & 9.080 & $\begin{array}{l}\text { Promulga a convenção sobre a conservação das espécies migratórias } \\
\text { de animais silvestres. }\end{array}$ & $\begin{array}{l}\text { Meio ambiente; } \\
\text { Animais }\end{array}$ \\
\hline
\end{tabular}

Fonte: Elaborada pelos autores. 
Ao analisar tal resultado é possível concluir pela não atuação do Legislativo a favor da sustentabilidade. Verifica-se uma mínima atividade na elaboração de leis destinadas à proteção do meio ambiente e nada em relação à questão do desenvolvimento humano para o ciclo 2010-2017. Assim, pode-se afirmar que não há o comprometimento, necessário e urgente, do poder Legislativo, com a questão do desenvolvimento humano e sustentável, mesmo que a Constituição Federal assegure em seu artigo 225 que todos têm direito ao meio ambiente ecologicamente equilibrado, sendo este bem de uso comum do povo e essencial à sadia qualidade de vida.

A noção de desenvolvimento nacional e a qualidade de vida implicam a direta necessidade de que se garanta um meio ambiente equilibrado e sustentável, de modo que o poder público deve se preocupar com a elaboração de políticas públicas e leis ambientais, a fim de assegurar o bem-estar da população, tendo como parâmetro regulador sempre a ideia de sustentabilidade conforme diretrizes internacionais as quais o país ratificou e as incorporou na Constituição nacional.

Em um contexto global, assim como nacional, em que uma proteção ambiental mais expressiva se faz necessária, a realidade de atuação legislativa do Brasil se distancia muito daquilo que se espera daqueles que devem representar os interesses da população como um todo, da melhor forma. Como já mencionado, um meio ambiente equilibrado é direito de todos e essencial para a qualidade de vida. É dever do poder público, portanto, comprometer-se e elaborar normas jurídicas que se mostrem efetivas para garantir o desenvolvimento humano e sustentável conforme os ODS e diretrizes constitucionais.

Ainda nessa temática o governo brasileiro apresentou um relatório voluntário de acompanhamento dos Objetivos do Desenvolvimento Sustentável. Nesse relatório o governo optou por apresentar algumas iniciativas nos seguintes objetivos: pobreza (1), fome zero e agricultura sustentável (2), saúde e bem-estar (3), igualdade de gênero (5), indústria, inovação e infraestrutura (9), vida na água (14) e parcerias e meios de execução (17). E especificamente sobre a atuação do Legislativo foi criada em dezembro de 2016 a Frente Parlamentar Mista de Apoio aos Objetivos de Desenvolvimento Sustentável da ONU.

Essa ação suprapartidária reúne mais de 200 deputados federais e senadores (...). Entre as finalidades da Frente está a de manter e consolidar a ação conjunta em benefício de políticas voltadas para os ODS, bem como agir em defesa da regulamentação e discussão de leis de incentivo ao desenvolvimento sustentável (RELATÓRIO..., 2017. p. 40).

E os principais resultados apresentados são ações e programas de governo, muitos deles existentes antes da Agenda 2030, mas que atendem aos objetivos propostos, tais como: Política Nacional para os Recursos do Mar (2005), a lei 11.340/2006 (Lei Maria da Penha), a lei 13.104/2015 (prever o feminicídio como circunstância qualificadora do crime de homicídio), o Programa de Aquisição de Alimentos (PAA) criado em 2003. Nesse Programa o governo

adquire produtos da agricultura familiar, remunerando os produtores que fornecem alimentos a entidades socioassistenciais. As finalidades do programa estão ligadas ao cumprimento de diversos ODS na medida em que: i) incentiva a agricultura familiar, promovendo sua inclusão econômica e social, com fomento à produção sustentável, ao processamento de alimentos e industrialização e à geração de renda; ii) incentiva o consumo e a valorização dos alimentos produzidos pela agricultura familiar; iii) promove o acesso à alimentação, na quantidade, qualidade e regularidade necessárias, das pessoas em situação de insegurança alimentar e nutricional; iv) constitui estoques públicos de alimentos produzidos por agricultores familiares; e v) estimula o cooperativismo e o associativismo (RELATÓRIO..., 2017. p. 55).

Isso demonstra a pouca articulação do governo para o estabelecimento dos ODS rumo ao desenvolvimento humano e sustentável.

\section{CONSIDERAÇÕES FINAIS}

No Brasil, embora haja a constitucionalização do direito ao meio ambiente ecologicamente equilibrado, em que este é tratado como um direito fundamental, ainda constata-se a ausência de vontade política suficiente para intituir leis em favor do desenvolvimento sustentável e humano. Isso ficou evidente na pesquisa quantitativa da atuação legislativa nacional. 
No ano de 2015, no entanto, foi criada a Agenda 2030, que se caracteriza por ser um plano de alcance universal para o desenvolvimento sustentável, com a presença de objetivos e metas. Ou seja, cada país analisa a sua carência e promove ações a fim de alcançar o pleno desenvolvimento, buscando os objetivos, mas considerando a realidade nacional de cada país.

O governo brasileiro apresentou o primeiro Relatório Voluntário em 2017 com o foco em 7 dos 17 objetivos. Foram eles: erradicação da pobreza (1), fome zero e agricultura sustentável (2), saúde e bem-estar (3), igualdade de gênero (5), indústria, inovação e infraestrutura (9), vida na água (14) e parcerias e meios de efetivação (17). O relatório, no tocante à atuação legislativa, aponta para a criação de Comissões para permitir a instituição dos ODS no Brasil e faz menção às leis aprovadas e em vigor antes da Agenda 2030.

Os dados da tabela sobre os artigos científicos revelam que muito se estuda sobre sustentabilidade, desenvolvimento sustentável e meio ambiente. Verifica-se, contudo, que essa temática pouco tem se relacionado com a noção de cidades (espaço urbano) e desenvolvimento humano.

Dessa forma, ao se confrontar com as hipóteses traçadas no início do trabalho, pode-se afirmar que: (a) diferentemente do proposto não há uma correlação entre a pesquisa acadêmica e a atuação legislativa, tendo em vista a pouca relevância das questões de desenvolvimento sustentável e sustentabilidade apresentadas em forma de leis nacionais; e (b) não há uma relação de trabalho conjunto ou parceria entre a pesquisa e a preocupação acadêmicas com a atuação e preocupações legislativas com foco em concretizar a agenda protetiva constitucional e a pauta internacional.

Um ponto de aperfeiçoamento entre as ações desses grupos (acadêmicos e legisladores) seria um maior diálogo entre o que está sendo pesquisado e desenvolvido nas universidades e o que pode ser feito em âmbito legislativo. Uma articulação entre os dois grupos permitirá um avanço em direção ao desenvolvimento humano e sustentável.

\section{REFERÊNCIAS}

ARAÚJO, L. A. D.; NUNES JR., V. S. Curso de direito constitucional. São Paulo: Saraiva, 2004.

BECK, U. Sociedade de risco: rumo a uma outra modernidade. Tradução Sebastião Nascimento. São Paulo: Ed. $34,2011$.

BRUNDTLAND, G. H. (Org.). Nosso futuro comum. 2. ed. Rio de Janeiro: FGV, 1991.

FIORILLO, C. A. P.; FERREIRA, R. M. Tutela constitucional da defesa do meio ambiente como princípio da atividade econômica em face do denominado desenvolvimento sustentável. Revista Novos Estudos Jurídicos - NEJ, Itajaí: Ed. Universidade Vale do Itajaí, vol. 22, n. 2, p. 461-488, maio/ago. 2017.

FIORILLO, C. A. P. Curso de Direito Ambiental Brasileiro. 17. ed. São Paulo: Saraiva, 2017.

FREITAS, J. Sustentabilidade: direito ao futuro. 2. ed. Belo Horizonte: Fórum, 2012.

MILARÉ, E. Direito do ambiente: doutrina, jurisprudência, glossário. São Paulo: RT, 2004.

PINHEIRO, M. M. S. As liberdades humanas como bases do desenvolvimento: uma análise conceitual da abordagem das capacidades humanas de Amartya Sen (texto para discussão). Brasília; Rio de Janeiro: Instituto de Pesquisa Econômica Aplicada Ipea, 2012.

PROGRAMA DAS NAÇÕES UNIDAS PARA O DESENVOLVIMENTO - Pnud. Transformando nosso mundo: a agenda 2030 para o desenvolvimento sustentável. Traduzido do inglês pelo Centro de Informação das Nações Unidas para o Brasil (Unic Rio) e revisado pela Coordenadoria-Geral de Desenvolvimento Sustentável (CGDES) do Ministério das Relações Exteriores do Brasil. Última edição em 11 de fevereiro de 2016. Disponível em: <http://www.undp.org/content/dam/brazil/docs/agenda2030/undp-br-Agenda2030-completo-pt-br-2016.pdf>. Acesso em: 12 nov. 2016 a.

. Relatório de desenvolvimento humano 2014 (Sustentar o progresso humano: reduzir as vulnerabilidades e reforçar a resiliência). Nova lorque: Pnud. 2014.

. Relatório de desenvolvimento humano 2010 (A verdadeira riqueza das Nações: vias para o desenvolvimento humano). Nova lorque: Pnud. 2010.

$2016 b$.

Os objetivos de desenvolvimento sustentável. Disponível em: <http://www.pnud.org.br/ods.aspx>. Acesso em: 19 ago.

RELATÓRIO NACIONAL VOLUNTÁRIO SOBRE OS OBJETIVOS DE DESENVOLVIMENTO SUSTENTÁVEL: Brasil 2017. Secretaria de Governo da Presidência da República, Ministério do Planejamento, Desenvolvimento e Gestão. Brasília: Presidência da República, 2017.

SACHS, I. Caminhos para o desenvolvimento sustentável. Organização Paula Yone Stroh. Rio de Janeiro: Garamond, 2002. 
SEN, A. Desenvolvimento como liberdade. Tradução Laura Teixeira Motta. Revisão Ricardo Doniselli Mendes. São Paulo: Companhia das Letras, 2000.

TRUBEK, D. M.; ESSER, J. “Empirismo crítico” e os estudos jurídicos críticos norte-americanos: paradoxo, programa ou caixa de Pandora? Tradução Rafael A. F. Zanatta. Revisão Técnica Fávio de Sá e Silva. Revista de Estudos Empíricos em Direito, Rede de Pesquisa Empírica em Direito - Reed, vol. 1, n. 1, p. 210-244, jan. 2014. 